\title{
Succession of plant community composition and leaf functional traits in responding to karst rocky desertification in the Wushan County in Chongqing, China
}

\author{
D. Qi ${ }^{1}$, X. Wieneke $2,4, X$. Zhou $^{1}$, X. Jiang ${ }^{3}$ and P. Xue ${ }^{3}$ \\ ${ }^{1}$ Key laboratory of Eco-environments in the Three Gorges Reservoir Region (Ministry of Education), Chongqing Key \\ Laboratory of Plant Ecology and Resources Research in Three Gorges Reservoir Region, School of Life Sciences, \\ Southwest University, Chongqing 400715, P. R. China \\ 2 Animal Science Department, Oklahoma State University, Stillwater, OK, 74074 USA \\ ${ }^{3}$ The Forestry Academy of Chongqing, Chongqing, P. R. China \\ ${ }^{4}$ Corresponding author. Email: xuwen.wieneke@okstate.edu, phone: +01 605-651-1271
}

Keywords: Karst rocky desertification, Leaf functional traits, Plant-soil relationship, Raunkiaer's life-form, Soil properties, Vegetation.

\begin{abstract}
Karst rocky desertification (KRD) is a process of soil desertification, which leads to the decline of soil quality and biomass. We conducted a plant community survey in KRD areas in Chongqing, China. Our aims were to determine key soil properties that shape plant communities and to identify essential leaf functional traits (LFTs) in responding to the progression of KRD. The vegetation survey was carried in a total of twenty study sites (five replicates for four stages of KRD) in the Wushan County in Chongqing, China. Leaves were collected from all the species in every site and measured/calculated for five LFTs, namely, specific leaf area, leaf area, leaf thickness, leaf tissue density, and leaf dry matter content. Soil samples were collected in triplicates in each site to measure soil properties. We found that the overall richness and diversity of community decreased along with the progression of KRD. Phanerophytes predominated in all the KRD areas. Soil $\mathrm{pH}$ was the main determinant of vegetation structure. Leaves with lower area yet higher density had the optimal adaptability in KRD regions, which can be planted as pioneer vegetation to restore land in KRD regions.
\end{abstract}

Abbreviations: NKRD-No KRD, LKRD-Latent KRD, MKRD-Moderate KRD, SKRD-Severe KRD, SLA-Specific Leaf Area, LA-Leaf Area, LT-Leaf Thickness, LTD-Leaf Tissue Density, LDMC-Leaf Dry Matter Content, IV-Importance Value, RDRelative Density, RC-Relative Cover, RF-Relative Frequency, SOM-Soil Organic Matter, SFMC-Soil Field Moisture Capacity, SCMC-Soil Capillary Moisture Capacity, SBD-Soil Bulk Density, SP-Soil Porosity, SWC-Soil Water Content, ANOVA-Analyses of Variance, LSD-Least Significant Difference, Db-RDA-Distance-Based Redundancy Analysis, Lefse-LDA Effect Size.

Nomenclature: Cronquist (1984) for plants.

\section{Introduction}

Karst is a type of landscape, in which the eco-environment is fragile, and the land is susceptible to soil erosion (Wang et al. 2004b, Xiong et al. 2009) . Karst rocky desertification (KRD) is a process of land degradation, resulting in desert-like landscape. KRD is classified into no KRD (NKRD), latent KRD (LKRD), moderate KRD (MKRD), and severe KRD (SKRD) based on bedrock exposure and vegetation cover (Jiang et al. 2014). One of the major consequences of KRD is the deterioration of soil quality, characterizing with loss of soil, water and nutrient content and decline of soil capacity, productivity, and biomass (Xu et al. 2013, Li et al. 2016, Zhang et al. 2016). Additionally, soil in karst region is thin and inadequate to retain water. Altogether, karst areas have low environmental capacity and stability yet high ecosensibility and poverty rate (Xu and Zhang 2014a).

Soil property and vegetation are two of main factors related to the progression of KRD (Xu and Zhang 2014b). Soil properties such as $\mathrm{pH}$, water content, and nutrient accessibility have correlations with the severity of KRD (Wang et al. 2004a, Zhang et al. 2006). Similarly, vegetation cover and community composition change in accordance to the gradient of KRD (Zeng et al. 2007). The deforestation specifically occurs along with the progression of KRD (Jiang et al. 2014). Some restoration strategies are proposed to recover the ecosystem in KRD regions; one of methods is to anthropogenically increase well adapted plants to expand vegetation cover (Yongrong et al. 2008, Jiang et al. 2014). Some studies investigated plant communities and their succession in KRD regions in southwest of China, especially in Guizhou, Yunnan and Guangxi Zhuang Autonomous Region (Zeng et al. 2007, Zhao et al. 2014). Few case studies, however, documented KRD related vegetation and soil variables in Chongqing. Furthermore, little is focused on understanding the adaptive strategy of plants in KRD regions.

Plants are able to alternate their functional traits such as root and leaf to utilize resources to the maximum, thereby 
adapting to challenging environments (Diaz et al. 1998, Westoby and Wright 2006). Leaf functional traits (LFTs) are one of major characters for plants to facilitate environmental adaptations. For instance, specific leaf area (SLA) is positively correlated with leaf growth and turnover rates. Plants with higher SLA are more abundant in fertile soil (Wright et al. 2001, Wright et al. 2002). Moreover, thicker leaves (e.g., higher leaf density and leaf dry matter content) have better tolerance to limited water and nutrient resources (Antúnez et al. 2001, Nautiyal et al. 2002, Ackerly and Cornwell 2007). Although many studies focused on the causes and consequences of KRD, few aimed to associate the succession of plant community and LFTs reciprocating to the recession of KRD (Li et al. 2009, Yangbing et al. 2009, Bai et al. 2013, Li et al. 2015),

In this study, we investigated plant communities in karst regions in the Wushan County in Chongqing, China. We evaluated ten soil variables and five LFTs, namely specific leaf area (SLA), leaf area (LA), leaf thickness (LT), leaf tissue density (LTD), and leaf dry matter content (LDMC) in each stage of KRD, in order to understand the adaptive strategy of plants to unfavorable environments via the alternations of LFTs. Our hypotheses were 1) the alternations of soil properties owing to desertification significantly affected the vegetation and 2) plants alternated physiological features, such as LFTs to cope with harsh environments. More specifically, vegetation with smaller and/or thicker leaves had more advancements of reserving limited resources in SKRD regions. To address our hypotheses, we 1) conducted vegetation survey in KRD regions, 2) analyzed and determined the main driving factors shaping the plant community, and 3) identified LFTs that facilitate the adaptability of plants in SKRD areas.

\section{Materials and methods}

Study area

The Wushan County locates in the northeast Chongqing (N 30 $46^{\prime}-31^{\circ} 28^{\prime}$, E $109^{\circ} 33^{\prime}-110^{\circ} 11^{\prime}$ ), in which exists up to $96 \%$ mountain area (Fig. 1). The major soil types in KRD regions are Xanthic Ferralsols and Haplic Luvisols classified by following guidelines of Food and Agriculture Organization of the United Nations (FAO) (Gong 2001). The Xanthic Ferralsols mainly distribute in the hilly and low-mid mountain zone that is below $1500 \mathrm{~m}$ of altitude. The surface soil has 10-30 cm humus layer that is comprised of decomposed or semi-decomposed litters. The layer below humus is compacted illuvium with yellow or claybank color. The Haplic Luvisols mainly distribute in the karst landscape with anticlinal structure and neutral to slight alkaline soil $\mathrm{pH}$. The bed-
Figure 1. Map of the study field. The study field is located in the northeast Chongqing (N 30 $46^{\prime}-31^{\circ} 28^{\prime}$, E $\left.109^{\circ} 33^{\prime}-110^{\circ} 11^{\prime}\right)$. A total of twenty sampling areas $(20 \mathrm{~m} \times 20 \mathrm{~m})$ were set, five for each stage of KRD. No KRD (NKRD), latent KRD (LKRD), moderate KRD (MKRD), and severe KRD (SKRD).

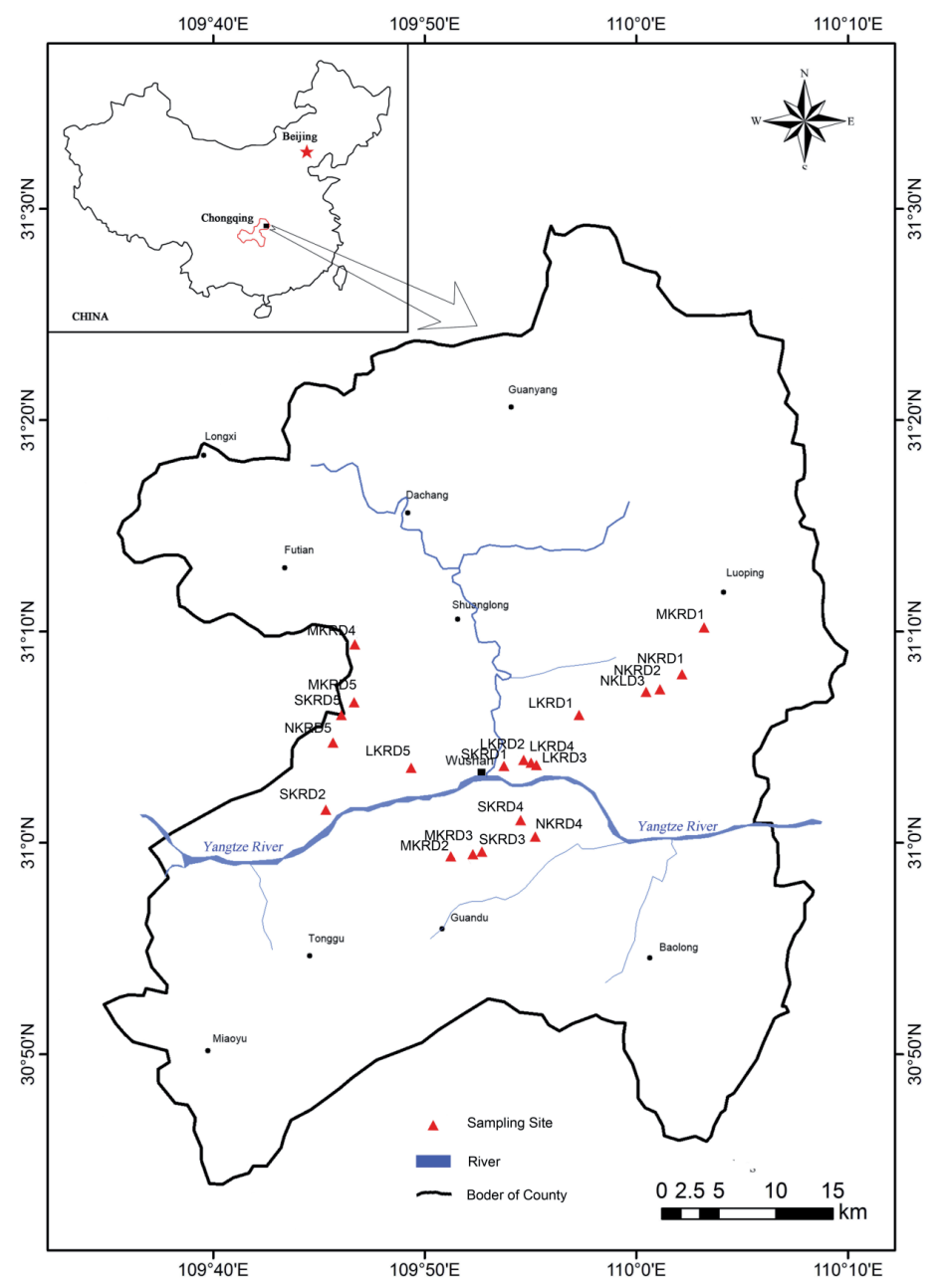


Table 1. Features and evaluations of karst rocky desertification (KRD) in different stages in this study.

\begin{tabular}{|c|c|c|c|c|}
\hline Study sites & NKRD & LKRD & MKRD & SKRD \\
\hline Coordinates & $\begin{array}{l}\text { N } 31^{\circ} 8^{\prime} 4^{\prime \prime} \text { E } 110^{\circ} 0^{\prime} 45^{\prime \prime} \\
\text { N } 31^{\circ} 9^{\prime} 1^{\prime \prime} \text { E } 110^{\circ} 1^{\prime} 31^{\prime \prime} \\
\text { N } 31^{\circ} 8^{\prime} 48^{\prime \prime} \text { E } 110^{\circ} 1^{\prime} 40^{\prime \prime} \\
\text { N } 31^{\circ} 7^{\prime} 54^{\prime \prime} \text { E } 110^{\circ} 0^{\prime} 6^{\prime \prime} \\
\text { N } 31^{\circ} 2^{\prime} 7^{\prime \prime} \text { E } 110^{\circ} 44^{\prime} 11^{\prime \prime}\end{array}$ & $\begin{array}{l}\text { N } 31^{\circ} 3^{\prime} 32^{\prime \prime} \text { E } 109^{\circ} 45^{\prime} 56^{\prime \prime} \\
\text { N } 31^{\circ} 0^{\prime} 45^{\prime \prime} \text { E } 109^{\circ} 54^{\prime} 28^{\prime \prime} \\
\text { N } 31^{\circ} 0^{\prime} 4^{\prime \prime} \text { E } 109^{\circ} 51^{\prime \prime} 8^{\prime \prime} \\
\text { N } 31^{\circ} 0^{\prime} 3^{\prime \prime} \text { E } 109^{\circ} 51^{\prime 2} 22^{\prime \prime} \\
\text { N } 31^{\circ} 4^{\prime} 21^{\prime \prime} \text { E } 109^{\circ} 48^{\prime} 59^{\prime \prime}\end{array}$ & $\begin{array}{l}\text { N } 31^{\circ} 50^{\prime} 56^{\prime \prime} \text { E } 110^{\circ} 2^{\prime} 41^{\prime \prime} \\
\text { N } 31^{\circ} 0^{\prime} 11^{\prime \prime} \text { E } 109^{\circ} 50^{\prime} 56^{\prime \prime} \\
\text { N } 31^{\circ} 0^{\prime} 26^{\prime \prime} \text { E } 109^{\circ} 52^{\prime} 16^{\prime \prime} \\
\text { N } 31^{\circ} 9^{\prime} 30^{\prime \prime} \text { E } 109^{\circ} 46^{\prime} 14^{\prime \prime} \\
\text { N } 31^{\circ} 7^{\prime} 27^{\prime \prime} \text { E } 109^{\circ} 45^{\prime} 24^{\prime \prime}\end{array}$ & $\begin{array}{l}\text { N } 31^{\circ} 4^{\prime} 42^{\prime \prime} \text { E } 109^{\circ} 54^{\prime} 25^{\prime \prime} \\
\text { N } 31^{\circ} 0^{\prime} 20^{\prime \prime} \text { E } 109^{\circ} 44^{\prime} 56^{\prime \prime} \\
\text { N } 31^{\circ} 0^{\prime} 15^{\prime \prime} \text { E } 109^{\circ} 51^{\prime} 53^{\prime \prime} \\
\text { N } 31^{\circ} 1^{\prime} 55^{\prime \prime} \text { E } 109^{\circ} 54^{\prime} 6^{\prime \prime} \\
\text { N } 31^{\circ} 6^{\prime} 49^{\prime \prime} \text { E } 109^{\circ} 44^{\prime} 34^{\prime \prime}\end{array}$ \\
\hline Altitude (m a.s.1.) & $850-1100$ & $750-1100$ & $850-1200$ & $900-1200$ \\
\hline Vegetation & Coniferous forest & Shrubland & shrub-grassland & shrub-grassland \\
\hline $\begin{array}{l}\text { Dominant plant } \\
\text { species }\end{array}$ & $\begin{array}{l}\text { Pinus massoniana } \\
\text { Quercus fabri } \\
\text { Pyracantha fortuneana } \\
\text { Rhus chinensis } \\
\text { Quercus serrata var. } \\
\text { brevipetiolata } \\
\text { Lespedeza floribunda } \\
\text { Miscanthus sinensis } \\
\text { Carex breviculmis } \\
\text { Arthraxon lanceolatus } \\
\text { Lophatherum gracile }\end{array}$ & $\begin{array}{l}\text { Cotinus coggygria } \\
\text { var. pubescens } \\
\text { Rosa cymosa } \\
\text { Coriaria nepalensis } \\
\text { Hypericum monogynum } \\
\text { A. lanceolatus } \\
\text { Heteropogon contortus } \\
\text { Carex brunnea } \\
\text { M. sinensis } \\
\text { Setaria viridis }\end{array}$ & $\begin{array}{l}\text { C. nepalensis } \\
\text { Abelia chinensis } \\
\text { Rubus niveus } \\
\text { R. chinensis } \\
\text { A. lanceolatus } \\
\text { Imperata koenigii } \\
\text { H. contortus } \\
\text { Gnaphalium affine } \\
\text { Conyza canadensis }\end{array}$ & $\begin{array}{l}\text { C. nepalensis } \\
\text { C. coggygria var. pubescens } \\
\text { R. chinensis } \\
\text { Jasminum floridum } \\
\text { A. lanceolatus } \\
\text { H. contortus } \\
\text { Eulaliopsis binata }\end{array}$ \\
\hline Vegetation cover $(\%)$ & $\geq 80$ & $\geq 80$ & $40-60$ & $15-30$ \\
\hline Bedrock & limestone & limestone & limestone & limestone \\
\hline $\begin{array}{l}\text { Bedrock exposure rate } \\
(\%)\end{array}$ & 0 & $0-30$ & $50-70$ & $>70$ \\
\hline Soil type & Xanthic Ferralsols & Haplic Luvisols & Haplic Luvisols & Haplic Luvisols \\
\hline Soil depth (cm) & $40-70$ & $20-40$ & $20-30$ & $10-20$ \\
\hline
\end{tabular}

The geographic location, vegetation type, and dominate species were summarized in the table. Classification of KRD is based on vegetation cover, soil depth and bedrock exposure rates. no KRD (NKRD), latent KRD (LKRD), moderate KRD (MKRD) and severe KRD (SKRD).

rock in study site is composed of limestone, clastic carbonate, and dolomite.

The susceptibility of land to desertification in the Wushan was determined via remote sensing (RS) and geographic information system (GIS) technologies in a previous study (Liu et al. 2011). The KRD susceptibility was evaluated on the basis of rocky property, topography, and vegetation. The assessment of KRD susceptibility integrates studies on the ecosystem in KRD regions and reveals the spatial distribution of desertification process. The overall KRD susceptibility in the Wushan County is that: $568 \mathrm{~km}^{2}(19 \%)$ of land is highly susceptible, $1498 \mathrm{~km}^{2}(51 \%)$ of land is susceptible, $685 \mathrm{~km}^{2}$ $(23 \%)$ of land is moderately susceptible, $6 \mathrm{~km}^{2}(0.2 \%)$ of land is slightly susceptible, and $199 \mathrm{~km}^{2}(7 \%)$ of land is not susceptible to KRD. In order to study functional traits and species distribution in responding to different stages of KRD process in this study, experimental sites were evaluated and classified into four groups, namely no KRD (NKRD), latent KRD (LKRD), moderate KRD (MKRD), and severe KRD (SKRD) based on vegetation cover rate and bedrock exposure rate (Table 1). The map of sampling sites is shown in Fig 1; a total of twenty sampling stations $(20 \mathrm{~m} \times 20 \mathrm{~m})$ were chosen, five for each stage of KRD.

\section{Plant community investigation}

The forest community existed in N- and LKRD areas, while the shrub-grassland community did in M- and SKRD. Plant community composition was evaluated using the typical quadrat sampling method. Each quadrat was chosen to represent common and/or dominant species, the endemics of the ecosystem and diversity, richness, and evenness of the community. Briefly, five quadrats $(20 \mathrm{~m} \times 20 \mathrm{~m})$ were chosen for each stage of KRD; three sub-quadrats $(6 \mathrm{~m} \times 6 \mathrm{~m})$ were randomly chosen within the quadrat frame. Each plot was divided into tree-, shrub- and grass-layers. All the trees, shrubs and grasses were investigated for the species, height, amount, density, and cover. Species importance value (IV) was used to represent the ecological dominance of species during community succession. The importance value was calculated as the sum of relative density (RD), relative cover (RC), and relative frequency $(\mathrm{RF}) . \mathrm{RD}=\mathrm{D}_{\mathrm{i}} / \sum \mathrm{D}_{\mathrm{i}}, \mathrm{RC}=\mathrm{C}_{\mathrm{i}} / \sum \mathrm{C}_{\mathrm{i}}$ and $\mathrm{RF}=$ $\mathrm{F}_{\mathrm{i}} / \sum \mathrm{F}_{\mathrm{i}}$, where $\mathrm{D}$ is the density, $\mathrm{i}$ is a species in the community, $\mathrm{C}$ is the cover, and $\mathrm{F}$ is the frequency. Margalef index $(\mathrm{R})$ was calculated to determine the richness of vegetation; Shannon index $(\mathrm{H})$ was for community diversity and Alatalo index $(\mathrm{E})$ was for evenness:

$$
R=(S-1) / \ln N
$$




$$
\begin{aligned}
& H=-\sum_{i=1}^{S} P_{i} \ln P_{i} \\
& E=\left[\left(\sum_{i=1}^{S} P_{i}^{2}\right)^{-1}-1\right] /\left[\exp \left(-\sum_{i=1}^{S} P_{i} \ln P_{i}\right)-1\right]
\end{aligned}
$$

where $\mathrm{S}$ is the total number of species in the community, $\mathrm{N}$ is the total number of individual in the community, and $\mathrm{P}_{\mathrm{i}}$ is the proportion of individuals found in a species.

\section{Soil variables measurement}

Soil samples in organic horizon $(0-20 \mathrm{~cm})$ were randomly collected in each quadrat in triplicates. All the soil samples were sent to the Key Laboratory of Eco-environments in Three Gorges Reservoir Region to measure the physicochemical properties by following the protocols described in the literature ( $\mathrm{Li}$ and Shao 2006). $\mathrm{pH}$, soil organic matter (SOM), soil field moisture capacity (SFMC), soil capillary moisture capacity (SCMC), soil bulk density (SBD), soil porosity (SP), and soil water content (SWC) were measured to represent soil properties. Vegetation cover, bedrock exposure rate, and soil depth were estimated in the field.

\section{Leaf functional traits measurement}

The entire vegetation was investigated in each sampling site; every species was carefully collected in triplicates. Five mature and healthy leaves from each plant were collected and measured for LFTs in triplicates. Leaves were scanned (CanoScan LiDR100, Cannon, Inc.) and then dried in $105^{\circ} \mathrm{C}$ for 15 minutes, followed by incubation in $60^{\circ} \mathrm{C}$ till constant weight. Five LFTs were evaluated in this study, namely LA, SLA, LT, LTD, and LDMC following the measurement instructions of the handbook (Pérez-Harguindeguy et al. 2013). Briefly, LT was measured at the position between the border and the midrib, between the tip and the base of the leaf; the important secondary veins was excluded. LA was calculated with the scanned images using software Image $J$ (Schneider et al. 2012). LTD was calculated by using leaf dry weight (LDW) divided by leaf volume (LV). SLA was calculated by using LA divided by LDW. And LDMC was calculated by using LDW divided by leaf fresh weight.

\section{Statistical analyses}

Sampling field map was generated by using Pearson Origin 8.6 (OriginLab, Northampton, MA). One-way analyses of variance (ANOVA), uncorrected Fisher's least significant difference (LSD) test and Pearson correlation analyses were performed by using R 3.3.2 statistical software (Team 2013). One-way ANOVA followed by uncorrected Fisher's LSD test were used to determine if soil properties and LFTs were significantly different in each KRD region. All the soil properties and LFTs had three biological- and technologicalreplicates. Soil properties were considered significantly different from one another if the $P$ value was lower than 0.05 .
The significant differences of LFTs in each sites were determined with the same criteria $(P<0.05)$.

The heat maps were generated by using the gplots package in R (Warnes et al. 2013). Heat maps were used to illustrate changing patterns of soil properties and LFTs in each KRD site. The dendrogram was used to show the similarity of soil properties and LFTs in KRD regions. Clustering was performed based on a matrix of Euclidean distances and complete linkage agglomeration. The Z-score was used to normalize data in order to demonstrate differences between samples. Colors white, yellow, and red, which can be interpreted as standard deviations from means, were assigned to each data point after $\mathrm{Z}$-scoring. The relative values were presented as red, yellow, and white colors, such that red indicated relatively high values, yellow was for relatively medium values, and white was for relatively low values.

Distance-based redundancy analysis (db-RDA) and Monte Carlo permutation test were performed by using vegan package in $\mathrm{R}$ (Oksanen et al. 2014). The db-RDA was used to perform the direct gradient analysis, which constrains and accumulates explanatory variables on the ordination axes (RDA1 and RDA2). In this study, db-RDA was employed to determine distribution patterns of species and to measure the amount of variations explained by soil variables. The plant community structure was represented by IVs of all the species found in sites. The importance values were used to estimate community composition instead of the count number of species due to the highly variable population in sites. More importantly, IV weights count, density, and frequency of a species within a community, truly reflecting how a species dominates in an area. The db-RDA was employed to partition species and to explore how soil properties variables explained variations of community compositions. The two ordination axes (RDA1 and RDA2) were constructed by constraining an entire set of explanatory variables, ten soil properties in this study. The spatial distribution of plant community structure and driving factors of soil properties were determined by using db-RDA. Significance was evaluated by Monte Carlo permutation test. Furthermore, the significance levels of soil properties shaping plant communities were evaluated by Monte Carlo permutation test (shown as $P$ values). Specifically, the Monte Carlo permutation approach ( $\mathrm{n}=999)$ was used to randomize and generate the statistical significant/ correct conclusion under a null hypothesis, which was that none of soil properties significantly affected plant community structure in this study.

LDA Effect Size (LEfSe) was used to determine plants that significantly responded to environmental changes (Segata et al. 2011). More specifically, the non-parametric factorial Kruskal-Wallis (KW) sum-rank test was first used to detect species with abundant differences among KRD regions $(P<0.05)$. The unpaired Wilcoxon rank-sum test was used to compare abundant differences of each species in all the KRD areas $(P<0.05)$. Linear Discriminant Analysis (LDA) was applied to calculate the effective size of each abundance difference. The LDA scores were normalized by $\log 10$. 
Table 2. Plant community composition in KRD regions.

\begin{tabular}{ccccccccccc}
\hline \multicolumn{3}{c}{ Shrub layer } & \multicolumn{1}{c}{ Grass layer } \\
\hline KRD & $\begin{array}{c}\text { Number of } \\
\text { species }\end{array}$ & $\mathrm{R}$ & $\mathrm{H}$ & $\mathrm{E}$ & KRD & $\begin{array}{c}\text { Number of } \\
\text { species }\end{array}$ & $\mathrm{R}$ & $\mathrm{H}$ & $\mathrm{E}$ \\
$\mathrm{NKRD}$ & 12 & $3.26 \mathrm{a}$ & $2.31 \mathrm{a}$ & $0.86 \mathrm{a}$ & NKRD & 6 & $1.32 \mathrm{c}$ & $1.55 \mathrm{c}$ & $0.79 \mathrm{a}$ \\
LKRD & 9 & $2.35 \mathrm{~b}$ & $2.02 \mathrm{~b}$ & $0.88 \mathrm{a}$ & LKRD & 8 & $1.65 \mathrm{~b}$ & $1.80 \mathrm{~b}$ & $0.83 \mathrm{a}$ \\
MKRD & 8 & $2.25 \mathrm{~b}$ & $1.92 \mathrm{~b}$ & $0.92 \mathrm{a}$ & MKRD & 9 & $1.89 \mathrm{a}$ & $2.04 \mathrm{a}$ & $0.89 \mathrm{a}$ \\
SKRD & 5 & $1.56 \mathrm{c}$ & $1.45 \mathrm{c}$ & $0.93 \mathrm{a}$ & SKRD & 5 & $1.13 \mathrm{~d}$ & $1.30 \mathrm{~d}$ & $0.83 \mathrm{a}$ \\
\hline
\end{tabular}

Analysis of variance (ANOVA) followed by uncorrected Fisher's LSD test were used to determine the significant difference between variables. Different letters are assigned to significant difference, $P<0.05$. no KRD (NKRD), latent KRD (LKRD), moderate KRD (MKRD) and severe KRD (SKRD). R, Margalef index for richness; $\mathrm{H}$, Shannon index for diversity and $\mathrm{E}$, Alatalo index for evenness.

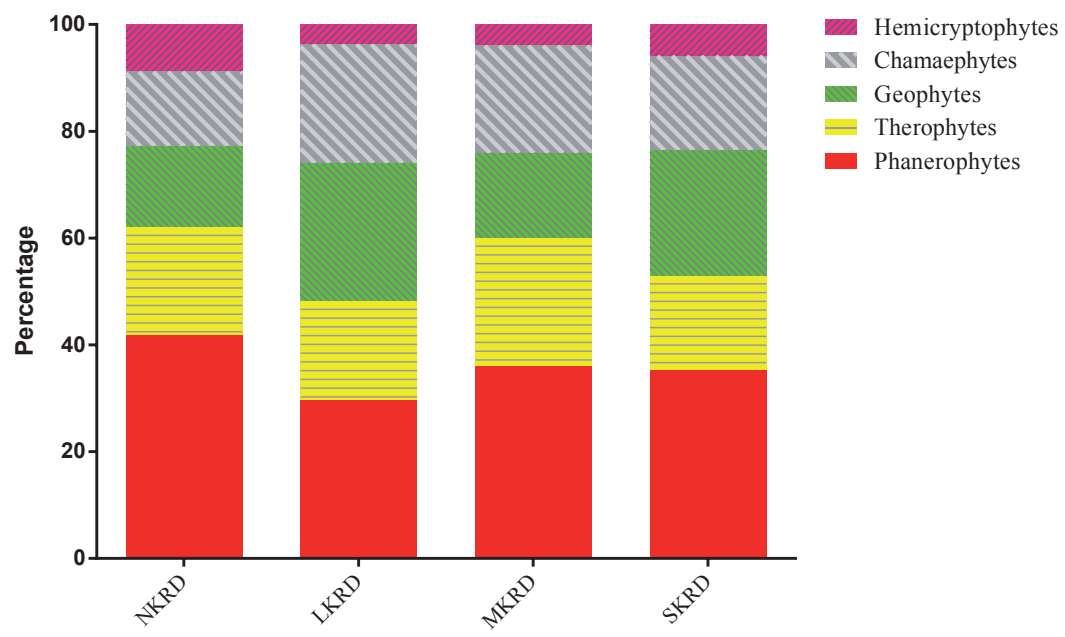

Figure 2. Summary of the plant community study. The $\mathrm{Y}$ axis is the absolute number of all the species found in each site. All the species were classified into Raunkiaer's life-form classes. No KRD (NKRD), latent KRD (LKRD), moderate KRD (MKRD), and severe KRD (SKRD).

\section{Results}

Plant community composition in different stages of KRD

To address the first aim, a vegetation survey was conducted in all the KRD sites. A total of 99 species were found in all the KRD areas. Detailed information on the plant community in each KRD region was listed in Table S1 (Electronic Supplement). Overall, Miscanthus sinensis, Coriaria nepalensis, Cotinus coggygria, Rhus chinensis, Arthraxon lanceolatus, and Heteropogon contortus were the most common species found in KRD regions. The diversity and richness of plant communities declined significantly $(P<0.05)$ along with the gradient of land desertification in shrub layer (Table $2)$. In grass layer, the overall trends of richness and diversity decreased significantly $(P<0.05)$ in accordance with the progression of KRD, with an exception found in MKRD sites. More specifically, only the richness and diversity in the grass layer in MKRD were significantly $(P<0.05)$ higher than them in the other of regions. Such exception did not necessarily indicate vegetation recovery in MKRD; it rather suggested that the deforestation and transition of primary layer from shrub to grass occurred significantly in MKRD.

All the species found in study fields were assigned to Raunkiaer's life-form classes (Raunkiaer 1934), namely phanerophytes, therophytes, geophytes, chamaephytes, and hemicryptophytes (Fig. 2). Overall, results showed that phanerophytes $(37.8 \%, 56$ species) predominated in all the KRD areas, followed by therophytes (20.3\%, 30 species), whereas geophytes $(18.2 \%, 27$ species) and chamaephytes $(16.9 \%$, 25 species) were the minorities. Hemicryptophytes $(6.8 \%$, 10 species) had least abundance; seven species were found in NKRD that belonged to hemicryptophytes, while one species was found in each degraded area. Furthermore, phanerophytes were mostly abundant in NKRD region $(41.8 \%)$. The predominance of phanerophytes was diluted by therophytes, geophytes, and chamaephytes in degraded areas.

\section{Soil variables and leaf functional traits in different stages of KRD}

To address the second aim, a total of ten soil properties and five LFTs were measured in KRD sites. One-way ANOVA (Table S2) was used to determine differences of soil properties among KRD areas. Overall, soil $\mathrm{pH}$, SCMC, SDB, SP, vegetation cover, bedrock exposure, and soil depth were significantly different along with progression of KRD. The relative comparisons and trends of soil variables in KRDs were shown as a heat map in Figure 3a. The clustering results indicated that soil variables in SKRD were quite different from those in NKRD. Fisher's uncorrelated LSD test was 
used to determine the significant differences of soil variables in each KRD region. Values of soil variables are shown in Table S4. Compared to those in NKRD sites, SOM, SP, and bedrock exposure increased significantly in SKRD regions; whereas vegetation cover and soil depth decreased significantly in SKRD areas $(P<0.05)$.

The changing trends of soil properties indicated that 1 ) soil $\mathrm{pH}$ significantly increased along with soil desertifica-
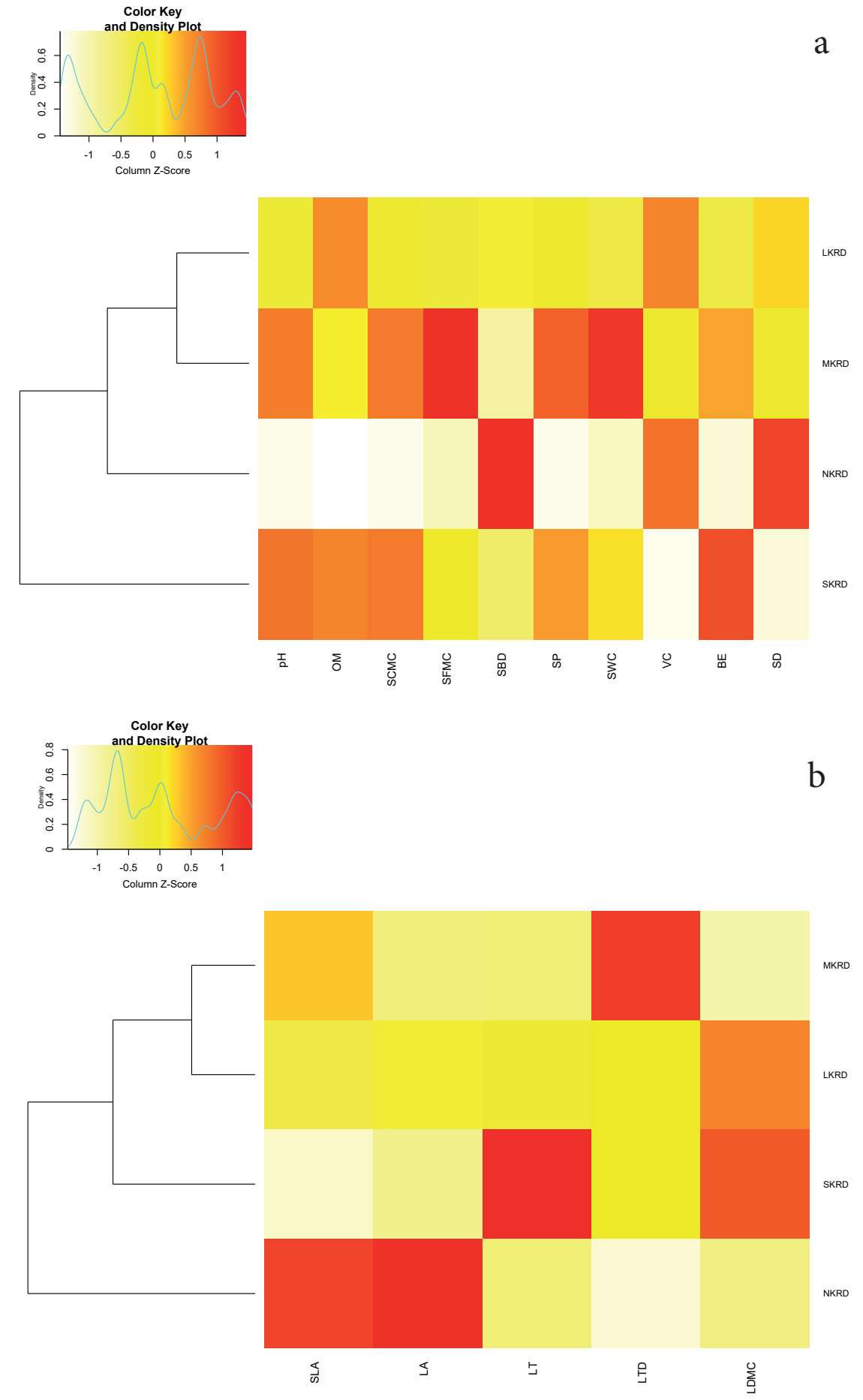

Figure 3. Heat maps of soil variables and leaf functional traits (LFTs) in KRD regions. a) Heat map of soil properties in KRD regions. b) Heat map shows the relative comparisons of LFTs. Clustering was based on a matrix of Euclidean distances. The relative values were presented as red, yellow, and white colors, where color red indicated relatively high values, yellow was for relatively medium values, and white was for relatively low values. No KRD (NKRD), latent KRD (LKRD), moderate KRD (MKRD), and severe KRD (SKRD). Specific leaf area (SLA), leaf area (LA), leaf thickness (LT), leaf tissue density (LTD), and leaf dry matter content (LDMC). 
Table 3. Monte Carlo permutation test of soil variables and plant community composition in KRD regions

\begin{tabular}{lccccc}
\hline Soil variables & RDA1 & RDA2 & R2 & F & p value \\
\hline pH & 0.926 & 0.303 & 0.417 & 12.895 & $0.001^{*}$ \\
VC & -0.657 & -0.702 & 0.068 & 2.236 & $0.008^{*}$ \\
SD & -0.822 & -0.450 & 0.064 & 2.271 & $0.014^{*}$ \\
SWC & 0.289 & 0.050 & 0.035 & 1.271 & 0.208 \\
BE & 0.874 & 0.449 & 0.031 & 1.139 & 0.330 \\
SP & 0.348 & 0.508 & 0.027 & 0.987 & 0.473 \\
SCMC & 0.661 & 0.230 & 0.029 & 1.078 & 0.387 \\
SBD & -0.351 & -0.504 & 0.032 & 1.178 & 0.303 \\
SFMC & 0.425 & 0.148 & 0.019 & 0.701 & 0.788 \\
OM & 0.412 & -0.067 & 0.018 & 0.637 & 0.779 \\
\hline
\end{tabular}

* $P<0.05$. Vegetation cover (VC), soil depth (SD), bedrock exposure (BE), organic matter (OM), soil field moisture capacity (SFMC), soil capillary moisture capacity (SCMC), soil bulk density (SBD), soil porosity (SP) and soil water content (SWC).

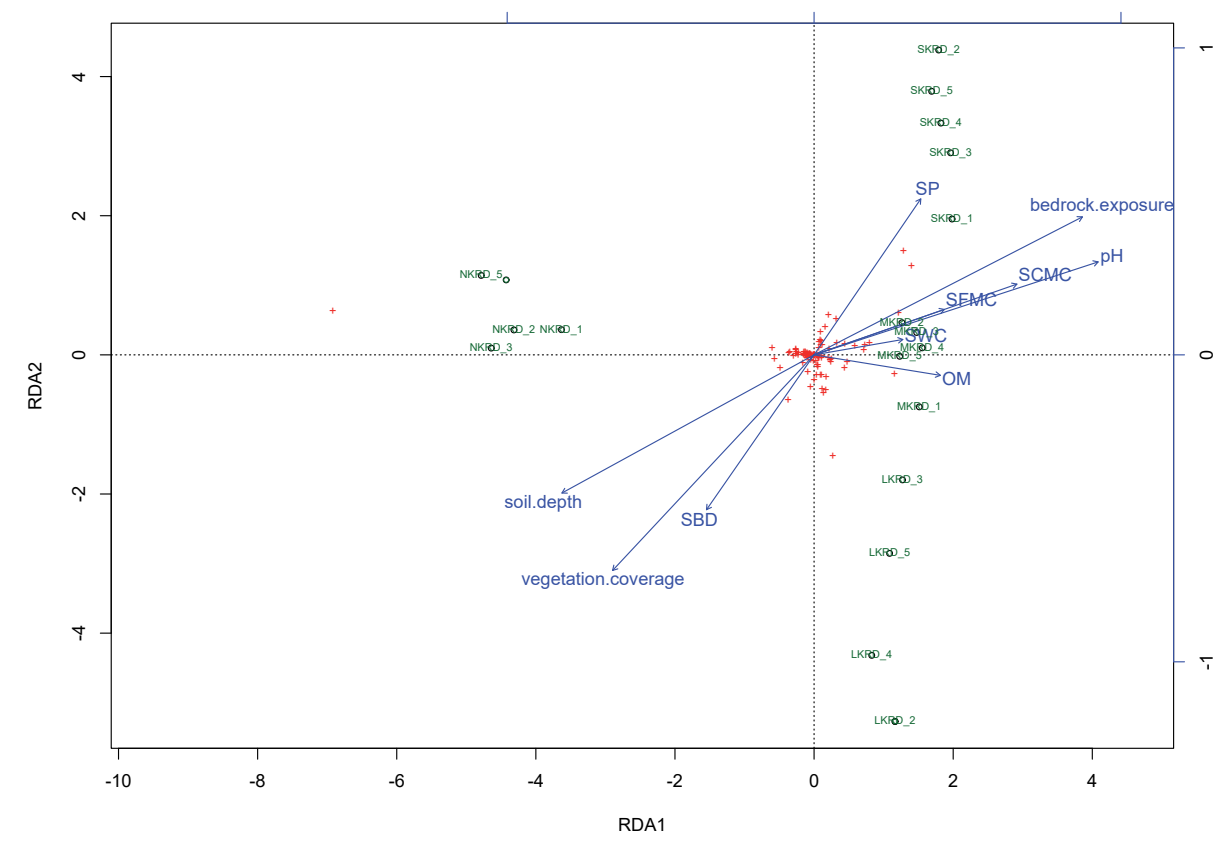

Figure 4. The distancebased redundancy analysis (db-RDA) diagram shows the relationship of soil variables with plant community composition in KRD areas. Each site was labeled in color green, where No KRD (NKRD), latent KRD (LKRD), moderate KRD (MKRD), and severe KRD (SKRD). Ten soil variables were labeled in color blue, where Soil organic matter (SOM), soil field moisture capacity (SFMC), soil capillary moisture capacity (SCMC), soil bulk density (SBD), soil porosity (SP), and soil water content (SWC). All the species are labeled by red crosses. tion due to soil erosion and parent material exposure, 2) the increased soil porosity in degraded land was due to the deterioration of soil physical structure, and 3) the higher soil surface runoff rate and bedrock exposure rate occurred in degraded soils. The overall trends of soil properties indicated the declines of soil fertility and soil health in SKRD areas. Furthermore, soil erosion not only caused loss of soil fertility, it also resulted in deterioration of soil physical structures. Larger soil porosity found in SKRD sites correlated with weaker water holding capacity. Soil with limited water holding capacity is saturated with water much sooner, excess water and certain nutrients are substantially easy to be washed out from top soil. Altogether, soil quality in SKRD region was significantly declined as indicated by high soil $\mathrm{pH}$, weak water holding capacity, and disturbed soil structure.
One-way ANOVA was used to determine differences of LFTs in KRD sites (Table S3). Overall, SLA, ST, STD, and LDMC were significantly different among KRD regions. The other heat map (Fig. 3b) showed the comparisons and changing trends of five LFTs in accordance to the progression of KRDs. Clustering results indicated that species with similar functional traits were mostly found in M- and LKRD areas; whereas species with particular LFTs in NKRD were remarkably different from those in severely degraded land. The clustering results demonstrated strong differences of functional traits distributed among degraded lands, especially between no desertification and severely degraded soil. One-way ANOVA results are showed in Table S4 and values of LFTs in KRDs are shown in Table S5. Overall, SLA and LA deceased significantly $(P<0.05)$ along with the land degradation slope. Values of SLA were found the lowest in 


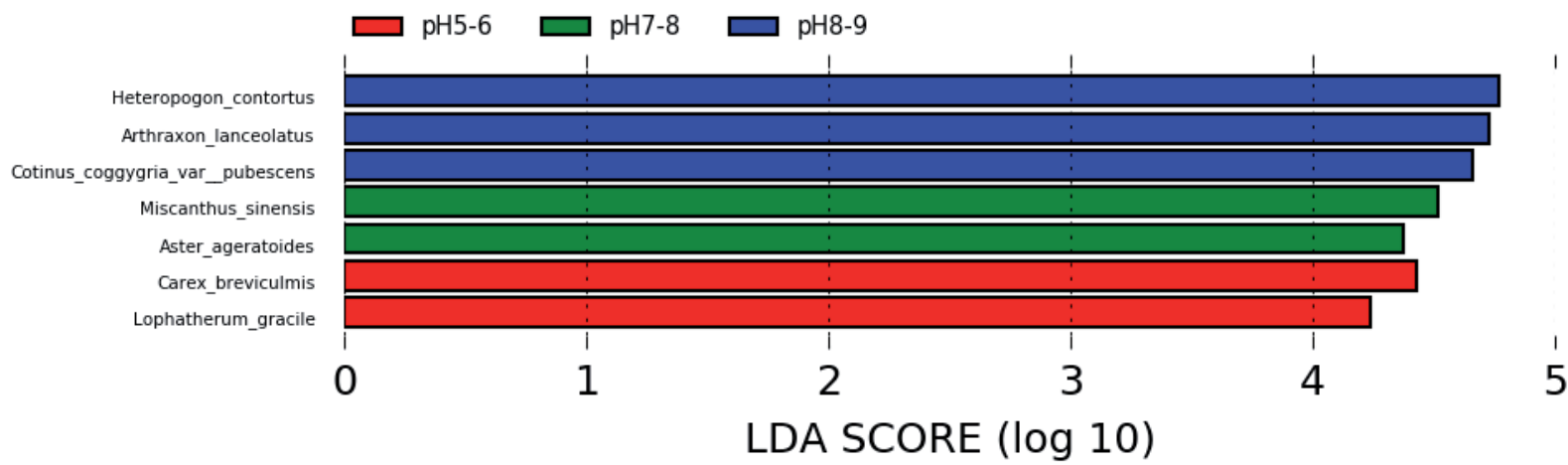

Figure 5. The LDA Effect Size (LEfSe) analysis identifies species which are significantly different among three soil pH ranges. $P<0.05$, logarithmic LDA score $=2.0$.

SKRD areas, indicating that plants with smallest SLA were the most abundant in SKRD sites. On the contrary, LT and LDMC were found the highest in SKRD regions, suggesting that plants with the thickest leaves predominated and adapted well in harsh environments. In summary, results demonstrated patterns of preferential distribution of functional traits in SKRD sites. More specifically, vegetation developed better surviving strategy by having smaller yet thicker leaves in severely degraded soils.

\section{Effects of soil variables on plant community composition}

The distance-based redundancy analysis (db-RDA) (Fig. 4) followed by Monte Carlo permutation test (Table 3) were used to test the first hypothesis, which suggested that certain soil properties significantly affected plant community structure. The db-RDA elucidated the distribution patterns of species responded to a set of ten soil properties in KRD regions. The combination of ten soil variables had significant correlation with vegetation structure $(F=2.6, P<0.001)$. All the environmental factors explained $74.2 \%$ of the community variation, whereas $25.8 \%$ of the variation was not explained by any of the factors. Within the explainable portion, RDA1 captured $64.3 \%$ of variation, while RDA 2 had $11.0 \%$ of variation. Along RDA1, $\mathrm{pH}\left(\mathrm{r}^{2}=0.417\right)$ was the most important determinant for plant community composition, followed by vegetation cover $\left(\mathrm{r}^{2}=0.068\right)$ and soil depth $\left(\mathrm{r}^{2}=0.064\right)$. On the second axis (RDA2), SBD $\left(r^{2}=0.032\right)$, bedrock exposure $\left(\mathrm{r}^{2}=0.031\right)$, and SP $\left(\mathrm{r}^{2}=0.030\right)$ were found affecting vegetation. The db-RDA results indicated that soil $\mathrm{pH}$ was the major driving factor shaping the plant community.

In order to further illustrate community differences among KRD regions in higher resolution, the LEfSe analysis (Fig. 5) was used to identify species that responded significantly to $\mathrm{pH}$ ( $\mathrm{pH} 5-6,7-8$ and 8-9). LEfSe results were calculated on the basis of non-parametric factorial Kruskal-Wallis (KW) sum-rank test to detect species with significant differences in abundance $(P<0.05)$. Results showed that $C$. breviculmis and $L$. gracile were the most abundant in soil with $\mathrm{pH} 5-6$ (NKRD). The dominance of C. breviculmis and L. gracile in
NKRD might be explained as 1) C. breviculmis and L. gracile showed preferences for acidic soil and 2) C. breviculmis and $L$. gracile are shade-tolerant plants that commonly colonized under Pinus massoniana, which were found plenty in NKRD areas. $M$. sinensis and A. ageratoides were the most abundant plants in regions with $\mathrm{pH}$ 7-8 (L- and MKRD). Both $M$. sinensis and $A$. ageratoides are rapidly growing plants with high reproductive rates to outcompete other species, which ascribe to the predominance of these two species in neutral and slightly alkaline soil. H. contortus, A. lanceolatus, and $C$. coggygria dominated in land of $\mathrm{pH}$ 8-9 (SKRD), indicating that plants that were xenophile and calciphile adapted well in harsh environment. More specially, the dominant plants in SKRD were featured with well-developed roots, high metabolic efficiency, and high alkali tolerance.

\section{Discussion}

We found that the diversity and richness of vegetation declined in response to progression of KRD in the Wushan County in Chongqing, China. We further determined that soil $\mathrm{pH}$ was the key driving factor in shaping plant communities in KRD regions, followed by vegetation cover rate, and soil depth. Moreover, we found that plants with thicker leaf and smaller leaf area had the best adaptability in SKRD areas. This study fills the knowledge gap of vegetation evaluation in KRD regions in Chongqing, identifies species that thrive in SKRD land, and paves the pathway of promoting vegetation cover as part of land restoration plan in KRD areas.

The progression of KRD threatens ecosystem, deteriorates soil quality, and affects geomorphology globally. Soil functions such as facilitating vegetation growth, regulating water supplies, and recycling nutrients are impaired due to soil desertification. With an increasing number of studies aiming to prevent KRD and restore soil conditions, one of the promising strategies is to promote the soil-plant interaction to facilitate soil recovery (Wang et al. 2004b, Xiao and Weng 2007, Peng and Wang 2012). The specific approach involves planting well-adapted species to increase vegetation cover and diversity, thereby preserving soil quality and content. Such method, however, can only be feasible when 
comprehensive information on vegetation and soil conditions is available in particular KRD regions. Different stages of KRD are characterized with different soil properties, to which plants have different surviving strategies.

To address our first aim, we found that the overall richness and diversity of vegetation significantly decreased along with the progression of KRD. Similar results reported in other studies also indicated that vegetation richness and diversity decrease with the succession of KRD in south China (Zeng et al. 2007, Sheng et al. 2016). Such deconstruction is mainly due to the degeneration of soil quality, for instance declining of water retention and soil depth, and hardening soil texture. Extreme climates like seasonal drought or flood often occur in the KRD regions owing to the weak soil capillarity, leading to inadequate water possession in soil (Hacke et al. 2000). The harsh environments hamper plants' physiological activities like photosynthesis, growth, and seeding; therefore, only limiting number of species with strong adaptive abilities can thrive in KRD areas (Liu et al. 2009).

By classifying plants into Raunkiaer's life-forms, we determined that phanerophytes were prevalent in all the KRD areas. Studying Raunkiaer's life-form helps to reveal the most striking features of plants in responding to unfavorable environments, weak soil water retention and high $\mathrm{pH}$ in our case. Phanerophytes use and store soil moisture effectively to enforce transpiration and photosynthesis in severe environments (Pariente 2002). Furthermore, unlike species with naked buds, phanerophytes which are equipped with scaled buds prevail in drought or cold environments (Nitta and Ohsawa 1998). The predominance of phanerophytes in KRD regions restrains the rates of soil erosion and nutrient loss in the soil.

To address our second aim, we found that soil $\mathrm{pH}$ was the main driving factor in shaping plant communities in KRD regions. The result is similar to previous studies suggesting that $\mathrm{pH}$ is the major determinant of vegetation richness (Caley and Schluter 1997, Chytrý et al. 2003, Tuomisto et al. 2014). High soil $\mathrm{pH}$ in $\mathrm{KRD}$ regions is mainly due to the erosion of the limestone. It is worth mentioning that soil water content positively correlates with $\mathrm{pH}$ in calcareous soil $(\mathrm{pH} \geq 7.2$ ) (Misra and Tyler 1999). Soil $\mathrm{pH}$ and moisture together serve as filters in the regional floras to separate calcicoles and calcifuges in calcareous soil. In this study, only the soil in the NKRD regions had a $\mathrm{pH}$ value lower than 7.0. Soil that underwent desertification had higher $\mathrm{pH}$ and water content. Soil $\mathrm{pH}$ and moisture synergistically impede up-taking nutrients in plants, which causes deterioration of vegetation (Misra and Tyler 1999). The progression of KRD affected plant community composition by causing selective soil conditions that only certain species could thrive. In this study, we found that $M$. sinensis and $A$. ageratoides predominated in L- and MKRD regions ( $\mathrm{pH} 7-8)$. C. breviculmis and L. gracile showed preferences in growing in SKRD ( $\mathrm{pH}$ 8-9), suggesting the potential plantation to increase vegetation cover.

Furthermore, we found that soil properties changed dramatically during the succession of KRD. Soil pH, SOM, SCMC, SFMC, SWC, SP, and bedrock exposure were higher in SKRD than in NKRD. SBD, vegetation cover, and soil depth were lower in SKRD. SP and SBD were negatively correlated. Lower SBD indicates higher water/air permeability and weaker soil water retention (Peng and Wang 2012). Thus, higher soil surface runoff rate and more loss of nutrients occur in SKRD regions. The results of this study are consistent with previous research, determining soil quality declines along with the aggravation of KRD (Lu et al. 2014, Xie et al. 2015). The structure of vegetation undergoes dynamic fluctuations as the results of the interaction between plants and soil properties (Westoby and Wright 2006). Thinner soil and higher bedrock exposure rate are unfavorable for trees and shrubs to colonize; therefore, the stratification is deformed along with the progression of KRD, and the grass-layer becomes the primary layer in SKRD. It is worth mentioning that even though SOM increased significantly, the higher content of SOM does not indicate better soil quality in SKRD areas. Possible explanations of high SOM content in SKRD sites are 1) the highly exposed and dissolved limestone results in higher SOM and 2) several annual herbs that predominate in SKRD regions are prone to produce litters contributing to the accumulated SOM content (Zhong et al. 2006).

The changes of LFTs significantly correlated with the gradient of KRD. To address the third aim, we found that SLA and LA significantly decreased in SKRD, whereas LT, LTD and LDMC significantly increased. Plants with lower SLA have longer leaf longevity, slower leaf turnover, and growth rates, and maximum photosynthetic rates (Kramer et al. 2000, Wright et al. 2001, Wright et al. 2002, Burns 2004). Species with thicker leaves also have longer leaf-lifespan owing to the lower photosynthetic rate (Wright et al. 2002, Escudero and Mediavilla 2003). Similarly, we found that vegetation with lower leaf area yet higher density predominated in SKRD areas. Our results are consistent with previous studies suggesting that the predominant species in barren land are the ones with leaves that have long life-spans, low growth rates, and high storage capacity of water and nutrients (Orwin et al. 2010).

LFTs indicate essential survival strategy and physiological alternations in reciprocating to progression of KRD. Soil variables in KRD regions, in turn, have directional effects on crucial LFTs for plants to adapt in KRD areas. We found that soil $\mathrm{pH}$ and SFMC had negative correlations with SLA and LA, while SBD had positive correlation with LDMC. The leaf plays important role in the plant-water transportation and regulation system, regarding transpiration, photosynthesis, and thermoregulation (Voncaemmerer and Farquhar 1981, Jarvis and McNaughton 1986, Collatz et al. 1991, Krause and Weis 1991). It is well established that small leaf size correlates with better adaptation for plants in the environment with low water and nutrient contents (McDonald et al. 2003, Yates et al. 2010). Soil in SKRD areas lacks of the water retention due to the thin soil layer and large bulk density. Small leaf addresses the limiting water resource via water loss control, by decreasing transpiration rate yet increasing stomatal density (Yates et al. 2010). Altogether, our results corroborate with previous studies, determining that high water permeable in soil drives the leaf development toward small leaf area. 
Higher LDMC indicates better storage capability of water and nutrients in plants (Lambers and Poorter 1992, Gower et al. 1993, Wright et al. 2005). Additionally, high LDMC is especially beneficial in drought due to the optimal water use efficiency (Song et al. 2008). Soils in SKRD regions have higher SBD, which indicates higher water permeability, thus weaker water retention ability. The positive correlation between SBD and LDMC reveals another surviving strategy of plants: compiling water in leaves to ensure the essential physiological functions.

Our results revealed community structures under the influences of KRD. The progression of desertification decreases plant diversity, richness, and cover in the land. We also determined the main environmental driving factors for shaping the plant community. Finally, we found relationships between soil properties and LFTs, and the dominating species that adapt well in SKRD areas.

The lack of continuous soil properties data, however, hinders us to reveal the relationships of soil variables with vegetation in a comprehensive perspective. Our plan is to conduct seasonal soil sampling and vegetation survey to systematically analyze the effects of KRD. Litter deposition and leaf nutrient contents also have impacts on soil properties. Wind, however, disturbs litter deposition in the study field and makes it difficult to collect samples. Microbiome affects plant distribution and nutrient up-taking. One of our ongoing studies is to understand how soil microbiome affects plant community composition in KRD areas using illumine HiSeq sequencing method.

Acknowledgements: This work is supported by the Chongqing Development and Reform Commission, grant number 104320-41009413. We are grateful to faculties and stuff from Chongqing Academy of Forestry, Chongqing Forestry Department and Key laboratory of Eco-environment in the Three Gorges Reservoir Region for all the supports and helps to accomplish our study.

\section{References}

Ackerly, D.D. and W. Cornwell. 2007. A trait-based approach to community assembly: partitioning of species trait values into within-and among-community components. Ecol. Lett. 10:135-145.

Antúnez, I., E.C. Retamosa and R. Villar. 2001. Relative growth rate in phylogenetically related deciduous and evergreen woody species. Oecologia 128:172-180.

Bai, X.Y., S.J. Wang and K.N. Xiong. 2013. Assessing spatial-temporal evolution processes of karst rocky desertification land: indications for restoration strategies. Land Degr. Dev. 24:47-56.

Burns, K. 2004. Patterns in specific leaf area and the structure of a temperate heath community. Divers. Distrib. 10:105-112.

Caley, M.J. and D. Schluter. 1997. The relationship between local and regional diversity. Ecology 78:70-80.

Chytrý, M., L. Tichý and J. Roleček. 2003. Local and regional patterns of species richness in Central European vegetation types along the pH/calcium gradient. Folia Geobot. 38:429-442.
Collatz, G.J., J.T. Ball, C. Grivet and J.A. Berry. 1991. Physiological and environmental-regulation of stomatal conductance, photosynthesis and transpiration - a model that includes a laminar boundary-layer. Agric. Forest Meteor. 54:107-136.

Cronquist, A. 1984. Polemoniaceae. Intermountain flora: vascular plants of the intermountain west, USA. 4:86-155.

Diaz, S., M. Cabido and F. Casanoves. 1998. Plant functional traits and environmental filters at a regional scale. J. Veg. Sci. 9:113122.

Escudero, A. and S. Mediavilla. 2003. Decline in photosynthetic nitrogen use efficiency with leaf age and nitrogen resorption as determinants of leaf life span. J. Ecol. 91:880-889.

Gong, Z. 2001. Chinese soil taxonomy. Science Press, Beijing.

Gower, S.T., P.B. Reich and Y. Son. 1993. Canopy dynamics and aboveground production of five tree species with different leaf longevities. Tree Physiol. 12:327-345.

Hacke, U.G., J.S. Sperry and J. Pittermann. 2000. Drought experience and cavitation resistance in six shrubs from the Great Basin, Utah. Basic Appl. Ecol. 1:31-41.

Jarvis, P.G. and K.G. McNaughton. 1986. Stomatal control of transpiration - scaling up from leaf to region. Adv. Ecol. Res. 15:1-49.

Jiang, Z., Y. Lian and X. Qin. 2014. Rocky desertification in Southwest China: impacts, causes, and restoration. Earth-Sci. Rev. 132:1-12.

Kramer, K., I. Leinonen and D. Loustau. 2000. The importance of phenology for the evaluation of impact of climate change on growth of boreal, temperate and Mediterranean forests ecosystems: an overview. Internat. J. Biometeor. 44:67-75.

Krause, G.H. and E. Weis. 1991. Chlorophyll fluorescence and photosynthesis - the basics. Annu. Rev. Plant Physiol. Plant Mol. Biol. 42:313-349.

Lambers, H. and H. Poorter. 1992. Inherent Variation in GrowthRate between Higher Plants - a Search for Physiological Causes and Ecological Consequences. Adv. Ecol. Res. 23:187-261.

Li, S., H.-d. Ren, X.-h. Yao, D. Zhang and Q. Dai. 2009. Study on characteristics of runoff and nutrition loss between different vegetation land in typical karst rock desertification zone. J. Soil Water Conserv. 2:001.

Li, Y. and M. Shao. 2006. Change of soil physical properties under long-term natural vegetation restoration in the Loess Plateau of China. J. Arid Environ. 64:77-96.

Li, Y., J. Xie, G. Luo, H. Yang and S. Wang. 2015. The evolution of a karst rocky desertification land ecosystem and its driving forces in the Houzhaihe Area, China. Open J. Ecol. 5:501.

Li, Y. B., Q. Y. Li, G. J. Luo, X. Y. Bai, Y. Y. Wang, S. J. Wang, J. Xie and G. B. Yang. 2016. Discussing the genesis of karst rocky desertification research based on the correlations between cropland and settlements in typical peak-cluster depressions. Solid Earth 7:741-750.

Liu, C., Y. Li, H. Yang, J. Min, C. Wang and H. Zhang. 2011. RS and GIS-based assessment for eco-environmental sensitivity of the Three Gorges Reservoir Area of Chongqing. Acta Geogr Sinica 66:631-642.

Liu, Y., Y. Xiong and D. C. Bassham. 2009. Autophagy is required for tolerance of drought and salt stress in plants. Autophagy 5:954-963.

Lu, X., H. Toda, F. Ding, S. Fang, W. Yang and H. Xu. 2014. Effect of vegetation types on chemical and biological properties of soils of karst ecosystems. Eur. J. Soil Biol. 61:49-57.

McDonald, P., C. Fonseca, J. Overton and M. Westoby. 2003. Leafsize divergence along rainfall and soil-nutrient gradients: is the 
method of size reduction common among clades? Funct Ecol. $17: 50-57$.

Misra, A. and G. Tyler. 1999. Influence of soil moisture on soil solution chemistry and concentrations of minerals in the calcicoles Phleum phleoides and Veronica spicata grown on a limestone soil. Ann. Bot. 84:401-410.

Nautiyal, P., N.R. Rachaputi and Y. Joshi. 2002. Moisture-deficitinduced changes in leaf-water content, leaf carbon exchange rate and biomass production in groundnut cultivars differing in specific leaf area. Field Crops Res. 74:67-79.

Nitta, I. and M. Ohsawa. 1998. Bud structure and shoot architecture of canopy and understorey evergreen broad-leaved trees at their northern limit in East Asia. Ann. Bot. 81:115-129.

Oksanen, J., F. Blanchet, R. Kindt, P. Legendre, P. Minchin, R. O’Hara, G. Simpson, P. Solymos, M. Stevens and H. Wagner. 2014. vegan: Community Ecology Package. R package version $2.1-41 / \mathrm{r} 2867$

Orwin, K.H., S.M. Buckland, D. Johnson, B.L. Turner, S. Smart, S Oakley and R.D. Bardgett. 2010. Linkages of plant traits to soil properties and the functioning of temperate grassland. J. Ecol. 98:1074-1083.

Pariente, S. 2002. Spatial patterns of soil moisture as affected by shrubs, in different climatic conditions. Environ. Monitor. Assess. 73:237-251.

Peng, T. and S.-j. Wang. 2012. Effects of land use, land cover and rainfall regimes on the surface runoff and soil loss on karst slopes in southwest China. Catena 90:53-62.

Pérez-Harguindeguy, N., S. Díaz, E. Garnier, S. Lavorel, H. Poorter, P. Jaureguiberry, M. Bret-Harte, W. Cornwell, J. Craine and D. Gurvich. 2013. New handbook for standardised measurement of plant functional traits worldwide. Aust. J. Bot. 61:167-234.

Raunkiaer, C. 1934. The Life Forms of Plants and Statistical Plant Geography; Being the Collected Papers of C. Raunkiaer. Clarendon Press, Oxford.

R Development Core Team. 2013. R: A language and environment for statistical computing. Vienna, Austria.

Schneider, C. A., W. S. Rasband and K. W. Eliceiri. 2012. NIH Image to ImageJ: 25 years of image analysis. Nat. Meth. 9:671-675.

Segata, N., J. Izard, L. Waldron, D. Gevers, L. Miropolsky, W. S. Garrett and C. Huttenhower. 2011. Metagenomic biomarker discovery and explanation. Genome Biol. 12:1.

Sheng, M., K. Xiong, L. Wang, X. Li, R. Li and X. Tian. 2016. Response of soil physical and chemical properties to Rocky desertification succession in South China Karst. Carbonates and Evaporites. doi: 10.1007/s13146-016-0295-4

Song, M., D. Duan, H. Chen, Q. Hu, F. Zhang, X. Xu, Y. Tian, H. Ouyang and C. Peng. 2008. Leaf $\delta 13 \mathrm{C}$ reflects ecosystem patterns and responses of alpine plants to the environments on the Tibetan Plateau. Ecography 31:499-508.

Tuomisto, H., G. Zuquim and G. Cárdenas. 2014. Species richness and diversity along edaphic and climatic gradients in Amazonia. Ecography 37:1034-1046.

Voncaemmerer, S. and G. D. Farquhar. 1981. Some relationships between the biochemistry of photosynthesis and the gas-exchange of leaves. Planta 153:376-387.

Wang, S. J., R. L. Li, C. X. Sun, D. F. Zhang, F. Q. Li, D. Q. Zhou, K. N. Xiong and Z. F. Zhou. 2004a. How types of carbonate rock assemblages constrain the distribution of karst rocky desertified land in Guizhou Province, PR China: phenomena and mechanisms. Land Degrad. Dev. 15:123-131.
Wang, S.J., Q.M. Liu and D.F. Zhang. 2004b. Karst rocky desertification in southwestern China: Geomorphology, landuse, impact and rehabilitation. Land Degrad. Dev. 15:115-121.

Wang, S., Yangbing, L. and L. Ruiling. 2003. Karst rocky desertification: formation background, evolution and comprehensive taming. Quaternary Sci. 6:008.

Warnes, G.R., B. Bolker, L. Bonebakker, R. Gentleman, W. Huber, A. Liaw, T. Lumley, M. Maechler, A. Magnusson and S. Moeller. 2013. gplots: Various R programming tools for plotting data. R package version 2.12. 1. Available online at: http:// CRAN. R-project. org/package $=$ gplots.

Westoby, M. and I. J. Wright. 2006. Land-plant ecology on the basis of functional traits. Trends Ecol. Evol. 21:261-268.

Wright, I. J., P. Reich and M. Westoby. 2001. Strategy shifts in leaf physiology, structure and nutrient content between species of high-and low-rainfall and high-and low-nutrient habitats. Funct. Ecol. 15:423-434.

Wright, I.J., P.B. Reich, J.H. Cornelissen, D.S. Falster, P.K. Groom, K. Hikosaka, W. Lee, C.H. Lusk, Ü. Niinemets and J. Oleksyn. 2005. Modulation of leaf economic traits and trait relationships by climate. Global Ecol. Biogeogr. 14:411-421.

Wright, I.J., M. Westoby and P.B. Reich. 2002. Convergence towards higher leaf mass per area in dry and nutrient-poor habitats has different consequences for leaf life span. J. Ecol. 90:534-543.

Xiao, H. and Q. Weng. 2007. The impact of land use and land cover changes on land surface temperature in a karst area of China. $J$. Environ. Manage. 85:245-257.

Xie, L., J. Zhong, F. Chen, F. Cao, J. Li and L. Wu. 2015. Evaluation of soil fertility in the succession of karst rocky desertification using principal component analysis. Solid Earth 6:515.

Xiong, Y.J., G.Y. Qiu, D.K. Mo, H. Lin, H. Sun, Q.X. Wang, S.H. Zhao and J. Yin. 2009. Rocky desertification and its causes in karst areas: a case study in Yongshun County, Hunan Province, China. Environ. Geol. 57:1481-1488.

$\mathrm{Xu}$, E. and H. Zhang. 2014a. Characterization and interaction of driving factors in karst rocky desertification: a case study from Changshun, China. Solid Earth 5:1329.

Xu, E., H. Zhang and M. Li. 2013. Mining spatial information to investigate the evolution of karst rocky desertification and its human driving forces in Changshun, China. Sci. Total Environ. 458:419-426.

Xu, E.Q. and H.Q. Zhang. 2014b. Characterization and interaction of driving factors in karst rocky desertification: a case study from Changshun, China. Solid Earth 5:1329-1340.

Yangbing, L., S. Jingan, Y. Hua and B. X. Yong. 2009. The relations between land use and karst rocky desertification in a typical karst area, China. Environ. Geol. 57:621-627.

Yates, M.J., G.A. Verboom, A.G. Rebelo and M.D. Cramer 2010. Ecophysiological significance of leaf size variation in Proteaceae from the Cape Floristic Region. Funct. Ecol. 24:485-492.

Yongrong, Q., L. Xuhui, Z. Zhongliang, Z. Chunmei and L. Chongyu. 2008. Comparative study on phosphorus contents of soil in karst rocky desertification area during eco-restoration process in Guangxi Province. Agric. Sci. Technol. 9:141-144.

Zeng, F., W. Peng, T. Song, K. Wang, H. Wu, X. Song and Z. Zeng. 2007. Changes in vegetation after 22 years' natural restoration in the Karst disturbed area in northwestern Guangxi, China. Acta Ecol. Sinica 27:5110-5119. 
Zhang, J.Y., M.H. Dai, L.C. Wang, C.F. Zeng and W.C. Su. 2016. The challenge and future of rocky desertification control in karst areas in southwest China. Solid Earth 7:83-91.

Zhang, P., L. Li, G. Pan and J. Ren. 2006. Soil quality changes in land degradation as indicated by soil chemical, biochemical and microbiological properties in a karst area of southwest Guizhou, China. Environ. Geol. 51:609-619.

Zhao, J., S. Li, X. He, L. Liu and K. Wang. 2014. The soil biota composition along a progressive succession of secondary vegetation in a karst area. PloS one 9:e112436.

Zhong, Y., J. Tang and L. Wang. 2006. Distribution characteristic of soil organic carbon in Three Gorges Reservoir District. J. Soil Water Conserv. 20:73-76.

Received April 5, 2017

Revised July 4, 2017 Accepted August 17, 2017
Open Access. This article is distributed under the terms of the Creative Commons Attribution 4.0 International License (https:// creativecommons.org/licenses/by/4.0/), which permits unrestricted use, distribution, and reproduction in any medium, provided the original author and source are credited, you give a link to the Creative Commons License, and indicate if changes were made.

\section{Electronic Supplement}

Table S1. Summary of species survey.

Table S2. One-way ANOVA results of soil properties.

Table S3. One-way ANOVA results of leaf functional traits.

Table S4. Soil variables in KRD regions.

Table S5. Leaf functional traits in KRD regions.

The tables may be downloaded from www.akademiai.com. 